Original Research Article

\title{
Prospective, randomized double blind comparative study of safety and efficacy of carvedilol versus atenolol in patients of mild to moderate hypertension
}

\author{
Swathi Ratnam R. ${ }^{1}$, Usha Kiran P. ${ }^{2}$, S. V. R. Rajasekhar ${ }^{3}$, M. Prasad Naidu ${ }^{4 *}$
}

${ }^{1}$ Department of Pharmacology, NRI Institute of Medical Science, Sangivalasa,

Visakhapatnam 530026, Andhra Pradesh, India

${ }^{2}$ Department of Pharmacology, Rangaraya Medical College, Kakinada, Andhra Pradesh, India

${ }^{3}$ Department of Pathology, NRI Institute of Medical Science, Sangivalasa, Visakhapatnam 530026, Andhra Pradesh, India ${ }^{4}$ Department of Biochemistry, Narayana Medical College and Hospital, Chinthareddypalem, Nellore 524003, Andhra

Pradesh, India

Received: 19 April 2017

Accepted: 16 May 2017

*Correspondence to:

Dr. M. Prasad Naidu, Email: m.prasadnaidu@ ymail.com

Copyright: (C) the author(s), publisher and licensee Medip Academy. This is an openaccess article distributed under the terms of the Creative Commons Attribution NonCommercial License, which permits unrestricted noncommercial use, distribution, and reproduction in any medium, provided the original work is properly cited.

\begin{abstract}
Background: Carvedilol is a new cardiovascular compound with the combined pharmacologic properties of nonselective B-blockade and vasodilation. The Aim of the study was to compare the safety and antihypertensive efficacy of $25 \mathrm{mg}$ Carvedilol once daily with $50 \mathrm{mg}$ atenolol once daily in patients with mild to moderate essential hypertension.

Methods: This was a single center study conducted in Rangaraya Medical College, Kakinada. 80 eligible patients with mild to moderate hypertension were randomized to receive $25 \mathrm{mg}$ Carvedilol once daily (40 patients) or $50 \mathrm{mg}$ atenolol (40 patients) in a double-blind 12-week treatment phase. At each visit 0, 4, 8 and 12 weeks of treatment, sitting Blood Pressure (BP) and heart rate were measured. The effect on BP reduction within the group is compared by paired " $t$ "test and the effect on reduction of BP between two study groups compared by unpaired " $t$ ”test.

Results: After 12 weeks of treatment, the mean reduction of SBP (Systolic Blood Pressure) with carvedilol is $22.33 \pm 8.31 \mathrm{mmHg}$ with no Significant difference $(\mathrm{p}>0.05)$ compared to atenolol group mean reduction in SBP of 21.37 $\pm 10 \mathrm{~mm} \mathrm{Hg}$. The mean reduction in DBP (Diastolic Blood Pressure) after completion of the study in carvedilol group is $6.75 \pm 4.82 \mathrm{~mm} \mathrm{Hg}$ with no Significant difference $(\mathrm{p}>0.05)$ compared to atenolol group mean reduction in DBP of $8.55 \pm 5.25 \mathrm{~mm} \mathrm{Hg}$. No significant difference seen in the efficacy parameters of both the drugs. The incidence of adverse effects such as bradycardia, headache, nausea, vomiting, hypotension and rash is less with carvedilol.

Conclusions: In patients with mild to moderate hypertension, there was no statistically significant difference between efficacy of carvedilol or atenolol with regard to the degree of reduction in BP or the percentage of patients achieving a response to therapy but carvedilol showed a better safety profile when compared to atenolol.
\end{abstract}

Keywords: Atenolol, Blood pressure, Carvedilol, Essential hypertension

\section{INTRODUCTION}

Hypertension is emerging as a serious public health problem in developing countries. The prevalence of hypertension increases with advancing age. About 50\% 
of people between the age of 60-69 years old have hypertension and the prevalence is further increased beyond age $70 .{ }^{1}$ Elevated arterial pressure causes pathological changes in the vasculature and hypertrophy of the left ventricle. Hypertension doubles the risk of cardiovascular disease, including coronary heart disease (CHD), congestive heart failure (CHF), ischemic and hemorrhagic stroke, renal failure, peripheral arterial disease. $^{2}$ Increasing awareness and diagnosis of hypertension and improving control of blood pressure with appropriate treatment are considered critical public health initiatives to reduce cardiovascular morbidity and mortality. ${ }^{3}$ Hypertension is the most prevalent chronic disease in India with prevalence increasing rapidly both in urban and rural population. ${ }^{4}$ The prevalence of hypertension ranges from $20-40 \%$ in urban adults and 12 $17 \%$ among rural adults. The number of people with hypertension is projected to increase from 118 million in 2000 to 214 million in 2025.5 In India, $23.10 \%$ men and $22.60 \%$ women over 25 years old suffer from hypertension. It is released in may 2012 by WHO global health statistic 2012. Recent studies show that for every known person with hypertension in India, there may possibly be 2 persons with undiagnosed hypertention or prehypertension. With over 139 million patients, India accounts for $15 \%$ of worlds uncontrolled hypertension patients. ${ }^{6}$ Carvedilol is a new cardiovascular compound that exhibits two main pharmacologic properties at therapeutic doses. It is a nonselective, competitive $B$ adrenoceptor antagonist with no intrinsic sympathomimetic activity. ${ }^{7}$

Central to its antihypertensive effect is a reduction in total peripheral resistance mediated by competitive $\alpha$ adrenoceptor blockade. Clinical trials in patients with essential hypertension have shown 25 to $100 \mathrm{mg}$ Carvedilol once daily to be a safe and effective antihypertensive dosing regimen. Carvedilol also has demonstrated calcium channel blocking actions at higher concentrations in preclinical models, which may contribute to increasing blood flow in certain vascular beds. $^{8}$

Atenolol, a cardio selective B-blocking agent, is indicated for the treatment of essential hypertension at the recommended dosage of 50 to $100 \mathrm{mg}$ once daily. The purpose of this study was to compare the safety and antihypertensive efficacy of 25 to $50 \mathrm{mg}$ Carvedilol once daily with 50 to $100 \mathrm{mg}$ atenolol once daily in patients with mild to moderate essential hypertension. ${ }^{9}$

\section{METHODS}

The protocol for the study was approved by the Dr. N.T.R University of Health Sciences, Vijayawada Andhra Pradesh. According to JNC 7 classification. Basing on the inclusion criteria, patients of both sexes aged between 20 to 65 years attending medical outpatient department in the Government General Hospital, Kakinada, with newly diagnosed and untreated mild to moderate hypertension i.e. $120-139 / 80-89 \mathrm{mmHg}$ as mild/ prehypertension and 140-159/ 90-99mmHg as moderate/ stage 1 hypertension, a total of 126 patients were selected. Among 126 patients, 46 were excluded basing on exclusion criteria, which includes, the patients who are irregular in study groups, who are on concurrent therapy with other medications, those who are suffering with other comorbidities and those who were not willing to give consent. A total of 80 patients were enrolled in the study as per the selection criteria and randomly allocated to two groups with 40 patients each. Group A- n=40 who received Carvedilol $25 \mathrm{mg}$ Once daily morning dose and Group B- n=40 who received Atenolol 50mg Once daily morning dose. Both the group patients were treated for 12 weeks and following were assessed at $0,4,8$ and 12 weeks.

- Complete blood picture, Blood Urea, Serum Creatinine, Serum glutamic oxaloacetic transaminase (SGOT), Serum Glutamic Pyruvic Transaminase (SGPT) Aspartate aminotransferase (AST), Alanine aminotransferase (ALT) are better instead of Serum glutamic oxaloacetic transaminase (SGOT), Serum Glutamic Pyruvic Transaminase (SGPT) and analysis of urine for - Albumin, Sugar and Microscopy.

- $\quad$ ECG, recording of blood pressure (Average of three readings of blood pressure was taken in only sitting position as mentioned in methods in introduction with gap of 2 minutes in between each recording), heart rate.

- $\quad$ Side effects of the drugs

\section{Statistical analysis}

The data was presented as mean \pm SD. The effect on blood pressure reduction within the group was compared by paired " $t$ " test and the effect on reduction of blood pressure between two study groups was compared by unpaired " $t$ " test.

\section{RESULTS}

In the present study, the number of patients in the age group 41-50 years are the highest consisting of 19 $(47.5 \%)$ patients in group A and in the age group 51-60 years are the highest consisting of $15(37.5 \%)$ patients in group B.

Table 1: Distribution of age of patients in each study group.

\begin{tabular}{|lll|}
\hline Age in years & Group A & Group B \\
\hline $21-30$ & 0 & 0 \\
\hline $31-40$ & $8(20 \%)$ & $8(20 \%)$ \\
\hline $41-50$ & $19(47.5 \%)$ & $12(30 \%)$ \\
\hline $51-60$ & $9(22.5 \%)$ & $15(37.5 \%)$ \\
\hline$>60$ & $4(10 \%)$ & $5(12.5 \%)$ \\
\hline Total & 40 & 40 \\
\hline
\end{tabular}


In the present study the percentage of males enrolled is $71.2 \%$ and that of females is $28.8 \%$ with mild to moderate hypertension.

In the present study the reduction of mean systolic blood pressure $(\mathrm{mmHg})$ after completion of the study in group $A$ and group B are 22.33 \pm 3.44 and 21.35 \pm 4.26 respectively, with no significant difference in their reduction $(\mathrm{p}>0.05)$ (Table 2$)$.

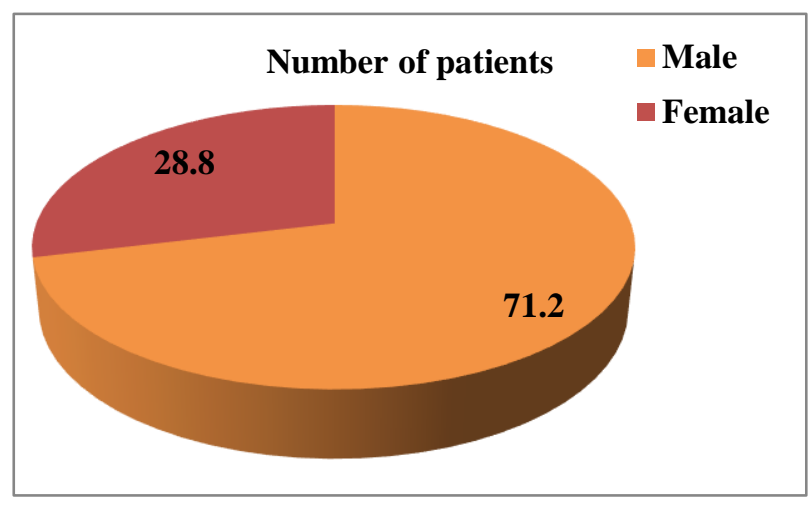

Figure 1: Distribution of gender in the study.

Table 2: Systolic blood pressure in between two study groups.

\begin{tabular}{|lll|}
\hline $\begin{array}{l}\text { Duration of } \\
\text { therapy }\end{array}$ & $\begin{array}{l}\text { Group A } \\
(\text { Mean } \pm \text { SD) }\end{array}$ & $\begin{array}{l}\text { Group B } \\
(\text { Mean } \pm \text { SD) }\end{array}$ \\
\hline At base line & $148.75 \pm 7.91$ & $148.35 \pm 8.94$ \\
\hline 4 weeks & $135.05 \pm 6.33$ & $136.47 \pm 7.56$ \\
\hline 8 weeks & $128.85 \pm 6.57$ & $127.37 \pm 4.11$ \\
\hline 12 weeks & $126.42 \pm 4.47$ & $127 \pm 4.68$ \\
\hline
\end{tabular}

In the present study the reduction of mean diastolic blood pressure $(\mathrm{mmHg})$ after completion of the study in group A and group B are $6.75 \pm 1.69$ and $8.55 \pm 1.18$ respectively, with no significant difference $(\mathrm{p}>0.05)$.

Table 3: Reduction in diastolic blood pressure in between two study groups.

\begin{tabular}{|l|l|l|}
\hline $\begin{array}{l}\text { Duration of } \\
\text { therapy }\end{array}$ & $\begin{array}{l}\text { Group A } \\
(\text { Mean } \pm \text { SD })\end{array}$ & $\begin{array}{l}\text { Group B } \\
(\text { Mean } \pm \text { SD })\end{array}$ \\
\hline At base line & $90.25 \pm 4.10$ & $91.97 \pm 3.99$ \\
\hline 4 weeks & $83.572 \pm 2.87$ & $85.10 \pm 2.85$ \\
\hline 8 weeks & $83.37 \pm 2.49$ & $83.67 \pm 3.00$ \\
\hline 12 weeks & $83.5 \pm 2.41$ & $83.42 \pm 2.809$ \\
\hline
\end{tabular}

Table 4: Mean heart rate (beats/min) in between two study groups.

\begin{tabular}{|lll|}
\hline $\begin{array}{l}\text { Duration of } \\
\text { therapy }\end{array}$ & $\begin{array}{l}\text { Group A } \\
(\text { Mean } \pm \text { SD })\end{array}$ & $\begin{array}{l}\text { Group B } \\
(\text { Mean } \pm \text { SD })\end{array}$ \\
\hline At base line & $80.7 \pm 2.80$ & $82.65 \pm 2.78$ \\
\hline 4 weeks & $77.9 \pm 4.21$ & $80.32 \pm 3.24$ \\
\hline 8 weeks & $77.55 \pm 4.26$ & $79.6 \pm 2.72$ \\
\hline 12 weeks & $75.12 \pm 5.17$ & $63.55 \pm 8.71$ \\
\hline
\end{tabular}

In the present study the reduction in mean heart rate (beats/min) after 12 weeks of the study in group A and group B are $5.58 \pm 2.37$ and $19.1 \pm 5.93$ respectively, showed significant difference $(\mathrm{p}<0.05)$.

In the total study, bradycardia is seen in $7.5 \%$ (3) patients in group A and $15 \%$ (6) patients in group B. Headache is seen in $10 \%$ (4) patients in group A and 15\%(6) patients in group B. Nausea is seen in 5\% (2) patient in group A and $10 \%$ (4) patient in group B. Vomiting is seen in $2.5 \%$ (1) patients in group A and 10\% (4) patients in group B. Dizziness is seen in $10 \%$ (4) patients in group A and $5 \%$ (2) patients in group B. Rhinitis is seen in $2.5 \%$ (1) patients and insomnia is seen in 5\% (2) patients in group A only. Rash is seen in $2.5 \%$ (1) patients and Hypotension is seen in $2.5 \%$ (1) patients in group B only.

Table 5: Occurrence of side effects (safety parameters) in both groups.

\begin{tabular}{|lll|}
\hline Side effect & $\begin{array}{l}\text { Group A } \\
\text { (carvedilol 25mg) }\end{array}$ & $\begin{array}{l}\text { Group B } \\
\text { (atenolol 50mg) }\end{array}$ \\
\hline Bradycardia & $3(7.5 \%)$ & $6(15 \%)$ \\
\hline Headache & $4(10 \%)$ & $6(15 \%)$ \\
\hline Nausea & $2(5 \%)$ & $4(10 \%)$ \\
\hline Vomiting & $1(2.5 \%)$ & $4(10 \%)$ \\
\hline Dizziness & $4(10 \%)$ & $2(5 \%)$ \\
\hline Insomnia & $2(5 \%)$ & 0 \\
\hline Rhinitis & $1(2.5 \%)$ & 0 \\
\hline Hypotension & 0 & $1(2.5 \%)$ \\
\hline Rash & 0 & $1(2.5 \%)$ \\
\hline
\end{tabular}

Table 6: Descriptive statistics for selective laboratory measurements (liver function tests, renal function tests).

\begin{tabular}{|c|c|c|c|c|}
\hline \multirow{2}{*}{$\begin{array}{l}\text { Laboratory } \\
\text { parameter }\end{array}$} & \multicolumn{2}{|c|}{$\begin{array}{l}\text { Group A } \\
\text { (carvedilol 25mg) }\end{array}$} & \multicolumn{2}{|c|}{$\begin{array}{l}\text { Group B } \\
\text { (Atenolol 50mg) }\end{array}$} \\
\hline & Baseline & Endpoint & Baseline & Endpoint \\
\hline \multicolumn{5}{|c|}{ Liver function test } \\
\hline ALT(U/L) & 17.9 & 17.7 & 18.6 & 18.2 \\
\hline AST (U/L) & 16.6 & 16.2 & 17.2 & 16.4 \\
\hline \multicolumn{5}{|c|}{ Renal function test } \\
\hline $\begin{array}{l}\text { Serum } \\
\text { creatinine } \\
(\mathrm{mg} / \mathrm{dL})\end{array}$ & 0.8 & 1 & 0.9 & 0.7 \\
\hline $\begin{array}{l}\text { Blood urea } \\
(\mathrm{mg} / \mathrm{dL})\end{array}$ & 14 & 14.6 & 16 & 16.4 \\
\hline
\end{tabular}

Liver function tests (ALT and AST), renal function tests (Table 6), ECG findings, Complete haemogram and urine analysis at enrollment and during assessment at $4^{\text {th }}, 8^{\text {th }}$ and 12 weeks (end of study) were normal and no abnormality detected for both the drugs.

\section{DISCUSSION}

High blood pressure (BP) is a major public health problem in India and elsewhere. The impact of hypertension on highly vascular organs such as kidney 
can be particularly devasting. In India hypertension is solely responsible for majority of deaths due to stroke and coronary heart diseases. ${ }^{10}$ Prospective Studies Collaboration has reported that reducing $\mathrm{BP}$ can substantially decrease cardiovascular risk. ${ }^{11}$ Anti hypertensives contribute in a major way in reduction of hypertension associated complications.

In the present study the number of patients in the age group 41-50 years are the highest consisting of 19 $(47.5 \%)$ patients in group A and in the age group 51-60 years are the highest consisting of $15(37.5 \%)$ patients in group B and there were $71.2 \%$ male patients and $28.8 \%$ female patients which were similar to study done by Luis M. Ruilope. ${ }^{7}$ Previous studies ${ }^{7,13}$ have compared the effects of carvedilol and atenolol on haemodynamic parameters in patients of mild to moderate essential hypertension. Like our study, there were no significant differences between the effects of carvedilol and atenolol on systolic and diastolic blood pressures during treatment. But the mean Heart Rate in present study showed significant difference $(\mathrm{p}<0.05)$ between group A and group B which is in contrast to previous studies. ${ }^{7,13}$

Our study showed dizziness (10\%) and headache (10\%) were more common with carvedilol similar to that of Luis M. Ruilope study. ${ }^{7}$ But bradycardia (15\%) and headache $(15 \%)$ were common with atenolol. Carvedilol and atenolol were equally effective and well-tolerated like widdman L study. ${ }^{14}$

\section{CONCLUSION}

Carvedilol is as effective as Atenolol in reducing systolic and diastolic blood pressure. The incidence of adverse effects such as bradycardia, headache, nausea, vomiting, hypotension and rash is less with carvedilol. Both the study drugs are equally effective in reducing the blood pressure but carvedilol showed a better safety profile when compared to atenolol.

\section{Funding: No funding sources}

Conflict of interest: None declared

Ethical approval: The study was approved by the Institutional Ethics Committee of Rangaraya Medical College, Kakinada

\section{REFERENCES}

1. Redon J. Hypertension and the metabolic syndrome. Manual of Hypertension of the European Society of Hypertension. 2008 Sep:303.

2. Chae CU, Pfeffer MA, Glynn RJ, Mitchell GF, Taylor JO, Hennekens CH. Increased pulse pressure and risk of heart failure in the elderly. Jama. 1999 Feb;281(7):634-43.

3. Levey AS, Eckardt KU, Tsukamoto Y, Levin A, Coresh J, Rossert J, et al. Definition and classification of chronic kidney disease: a position statement from Kidney Disease: Improving Global Outcomes (KDIGO). Kidney international. 2005 Jun;67(6):2089-100.

4. Chobanian AV, Bakris GL, Black HR, Cushman WC, Green LA, Izzo JL, et al. Seventh report of the joint national committee on prevention, detection, evaluation, and treatment of high blood pressure. hypertension. 2003 Dec;42(6):1206-52.

5. Biradar SS, Reddy S, Raju SA, Kapatae R. Assessment of pharmacist mediated patient counseling on knowledge, attitude and practices on hypertension in compliance with antihypertensive drugs in South Indian city. International Journal of Pharmacy and Life Sciences. 2012 Jun;3(6).

6. Prince MJ, Ebrahim S, Acosta D, Ferri CP, Guerra M, Huang Y, et al. Hypertension prevalence, awareness, treatment and control among older people in Latin America, India and China: a 10/66 crosssectional population-based survey. Journal of hypertension. 2012 Jan 1;30(1):177-87.

7. Ruilope LM. Comparison of a new vasodilating $\beta$ blocker, carvedilol, with atenolol in the treatment of mild to moderate essential hypertension. American journal of hypertension. $1994 \mathrm{Feb}$;(2):129-36.

8. Yancy CW, Fowler MB, Colucci WS, Gilbert EM, Bristow MR, Cohn JN, et al. Race and the response to adrenergic blockade with carvedilol in patients with chronic heart failure. New England Journal of Medicine. 2001 May;344(18):1358-65.

9. Wang L, Manson JE, Sesso HD. Calcium intake and risk of cardiovascular disease. American Journal of Cardiovascular Drugs. 2012 Apr;12(2):105-16.

10. Gupta R. Trends in hypertension epidemiology in India. Journal of human hypertension. 2004 Feb;18(2):73-8.

11. Prospective Studies Collaboration. Blood cholesterol and vascular mortality by age, sex, and blood pressure: a meta-analysis of individual data from 61 prospective studies with 55000 vascular deaths. The Lancet. 2007 Dec 7;370(9602):1829-39.

12. De la Sierra A, Segura J, Banegas JR, Gorostidi M, Juan J, Armario P, et al. Clinical features of 8295 patients with resistant hypertension classified on the basis of ambulatory blood pressure monitoring. Hypertension. 2011 May 1;57(5):898-902.

13. Young PH. A comparison of carvedilol with atenolol in the treatment of mild-to-moderate essential hypertension journal of cardiovascular pharmacology. 1992;19.

14. Widmann, L, van der Does R, Hörrmann M. Eur J Clin Pharmacol. 1990;38(2):143.

Cite this article as: Ratnam SR, Kiran UP, Rajasekhar SVR, Naidu MP. Prospective, randomized double blind comparative study of safety and efficacy of carvedilol versus atenolol in patients of mild to moderate hypertension. Int J Basic Clin Pharmacol 2017;6:1678-81. 